\title{
A RARE CASE OF EXTENSIVE THROMBOSIS OF INFERIOR VENA CAVA, PORTAL VEIN, SPLENIC VEIN AND SUPERIOR MESENTRIC VEIN
}

Giridhar Patili1, N. V. Nimbal2, Archana Dambal'3 , M. P. Madhavaranga ${ }^{4}$

\section{HOW TO CITE THIS ARTICLE:}

Giridhar Patil, N. V. Nimbal, Archana Dambal, M. P. Madhavaranga. "A Rare Case of Extensive Thrombosis of Inferior Vena Cava, Portal Vein, Splenic Vein and Superior Mesentric Vein". Journal of Evolution of Medical and Dental Sciences 2015; Vol. 4, Issue 19, March 05; Page: 3375-3378, DOI: 10.14260/jemds/2015/485

ABSTRACT: While the most common presentation of venous thromboembolic disease is deep vein thrombosis (DVT) or pulmonary thromboembolism, rarer manifestations are thrombosis of jugular vein, cerebral sinus and inferior vena cava. Here we are presenting a rare case of inferior vena caval thrombosis with multiple thrombus in portal vein, splenic vein and superior mesenteric vein.

KEYWORDS: Inferior vena caval thrombosis, deep vein thrombosis, anticoagulation.

INTRODUCTION: Inferior vena caval obstruction is caused by invasion or compression by pathological process, or thrombosis of the vein itself. In the U.S., incidence is estimated to be at 5-10 cases per 100,000 per year. ${ }^{1}$ Thrombosis of the inferior vena cava (IVC) has similar etiological factors to lower limb deep venous thrombosis (DVT). Hypercoagulability related to hematological or neoplastic abnormalities, venous stasis secondary to extra luminal pressure from tumors or inflammatory processes and vessel injury due to trauma have all been implicated as primary mechanisms in the pathophysiology of IVC thrombosis. The clinical presentation of inferior vena caval thrombosis varies, depending on extent and location of the thrombus. Because of the variability in signs and symptoms, using a classification system to describe the clinical features may aid in the diagnosis of inferior vena caval thrombosis. Thrombophilic screening and evaluation of the clotting and fibrinolytic systems may aid in the diagnosis of this condition. Contrast venography remains the criterion standard as the optimal diagnostic study for inferior vena caval thrombosis. Medical management of vena caval thrombosis focuses on anticoagulation and thrombolytic therapy. Surgical management of this condition consists of caval interruption, thrombectomy, or endovascular interventions.

CASE REPORT: A 30 years old male presented with history of distension of abdomen since 2 months, high coloured urine and yellowish discoloration of sclera since 12 days, pain in abdomen since 10 days and fever and vomiting since 2 days. Patient was referred, diagnosed as a case of Budd-Chiari syndrome.

Patient had similar complaints 2 months back for which he was treated conservatively at a private hospital and was relieved of his symptoms. He also had a past history of DVT 3 years back for which he was on a long term anticoagulant treatment with tab. warfarin 5mg.

Patient was a non-alcoholic, non-smoker, non-diabetic and non-hypertensive.

EXAMINATION: Patient's vitals were stable. He was pale, icteric, with pitting type of pedal edema present until the knee joint. Cardiovascular, respiratory and central nervous system were normal.

Per abdominal examination revealed uniformly distended abdomen with horizontally stretched umbilicus. Dilated, engorged and tortuous veins were seen at the flanks with direction of 
flow of blood below upwards, both below and above umbilicus. On palpation, tenderness was absent and there was hepatomegaly, $5 \mathrm{cms}$ and splenomegaly $2 \mathrm{cms}$ below the sub coastal margin respectively. Percussion revealed shifting dullness present. On auscultation, bowel sounds were present. No bruit heard.

INVESTIGATIONS: Haematological parameters were within normal limits. Urine routine revealed traces of albumin, absent urine sugar, bile salts and pigments and normal urobilinogen and microscopy. RBS, blood urea and serum creatinine were within normal limits. LFT revealed a total protein of $5.6 \mathrm{gm} / \mathrm{dl}$, albumin $2.7 \mathrm{gm} / \mathrm{dl}, \mathrm{A} / \mathrm{G}$ ratio of 0.9 , AST $56 \mathrm{U} / \mathrm{L}$, ALT $27.3 \mathrm{U} / \mathrm{L}$, alkaline phosphatase $124.7 \mathrm{U} / \mathrm{L}$, total bilirubin $2.7 \mathrm{mg} / \mathrm{dl}$ out of which direct was $1 \mathrm{mg} / \mathrm{dl}$ and indirect was $1.7 \mathrm{mg} / \mathrm{dl}$. Prothrombin time: test-35.25sec, control-12.5sec, ratio-2.77 and INR-2.77. HbsAg and HCV were negative. USG report showed hepatomegaly with features of cirrhosis, splenomegaly, and gross ascites. CT abdomen + pelvis (Oral \& IV contrast) revealed hepatosplenomegaly; thrombosis of portal vein \& it's right branch, splenic vein, superior mesenteric vein and inferior vena cava; collaterals in retroperitoneum, pelvic region, anterior abdominal wall, posterior spinal musculature; right sided varicocoele noted with gross ascites.

TREATMENT: Patient was treated with antibiotics, anticoagulants like Tab. Warfarin 5mg od \& inj. Clexane $40 \mathrm{U}$ s/c bd; Tab. Lasilactone bd. Patient was referred to higher centre for further investigations and management.

DISCUSSION: Thrombosis of the inferior vena cava (IVC) is an under-recognized entity with a variety of clinical presentations. From a global standpoint, IVC thrombosis represents a subset of DVT. The triad of stasis, vessel injury, and hypercoagulability formulated by Virchow remain the foundation for our understanding of the pathophysiology of DVT in general and for IVCT in particular.

Etiology of IVCT includes a wide range of conditions.

Tumors: renal cell carcinoma, seminomas and teratomas, retroperitoneal leiomyosarcoma. ${ }^{2}$, adrenal cortical carcinoma, and renal angiomyolipoma. ${ }^{3}$

Compression: Aneurysms of the abdominal aorta, Hepatic abscesses, polycystic disease of the right kidney, pancreatic pseudo cysts, acute pancreatitis.

Hematoma/Trauma: Psoas hematomas and other hematomas of the retroperitoneum, direct trauma to the IVC.

Dysfunctional coagulation System: nephrotic syndrome due to massive urinary protein loss, and diminished levels of antithrombin III.

Iatrogenic: hepatic transplantation, dialysis access, femoral venous catheters, pacemaker wires, and vena caval filters.

Other associated conditions: retroperitoneal fibrosis, pregnancy, and oral contraceptives.

Patients with inferior vena caval thrombosis (IVCT) may present with a spectrum of signs and symptoms. Patients may be asymptomatic, or they may present only after complications occur. 


\section{CASE REPORT}

Patients who have IVCT may present only after having a pulmonary embolism. In patients with complete absence of the IVC, symptoms associated with severe venous hypertension like bilateral lower extremity edema, varicose veins, nonhealing venous ulcers, caput medusae, other manifestations of collateral venous system hypertension/dilatation may form the clinical picture. ${ }^{4}$

Recent advances in the utilisation of ultrasound, CT and MRI imaging as well as endovascular procedures have resulted in an increase in detection rates of IVC anomalies as well as the incidental discovery of such abnormalities during unrelated investigations and therapeutic endovascular or surgical procedures. ${ }^{5}$ Contrast venography remains the standard for diagnosis of IVC thrombosis with a low false-positive rate and the advantage of access for immediate treatment if required.

Treatment options in the case of IVC thrombus without anatomical variance include anticoagulation, mechanical thrombectomy, systemic thrombolytic therapy, transcatheter regional thrombolysis, pulse-spray pharmaco mechanical thrombolysis and angioplasty. ${ }^{6}$

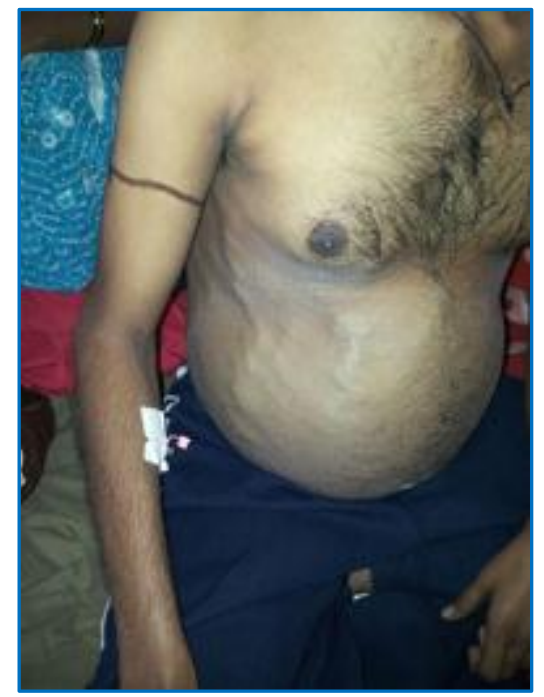

Fig. 1: Dilated abdominal wall veins

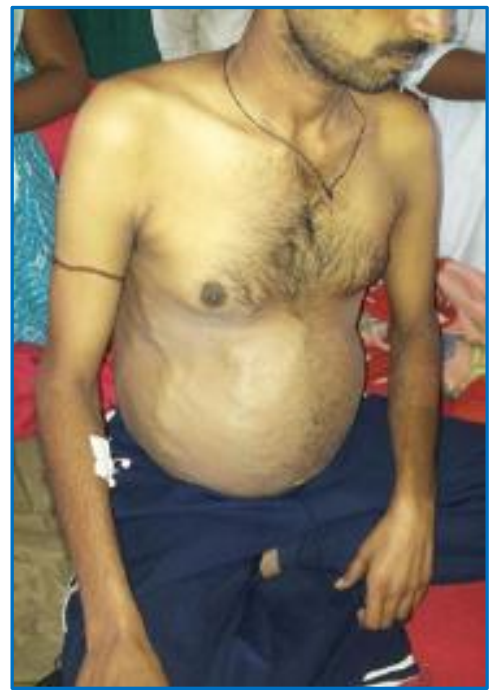

Fig. 2: Dilated abdominal wall veins

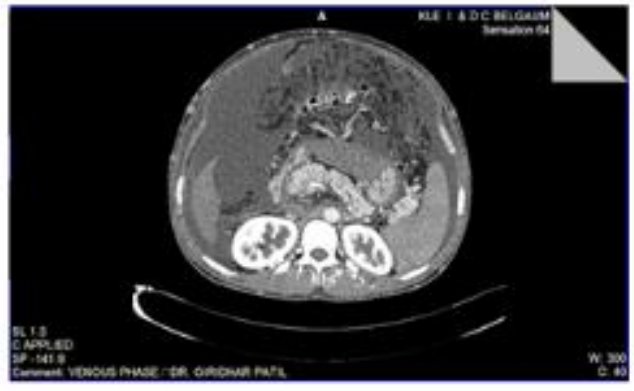

Fig. 3: CT Abdomen showing thrombus in IVC

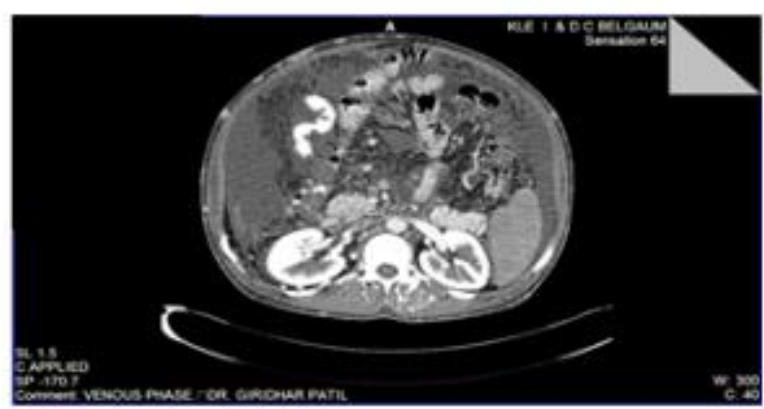

Fig. 4: CT Abdomen - thrombus in Portal vein 


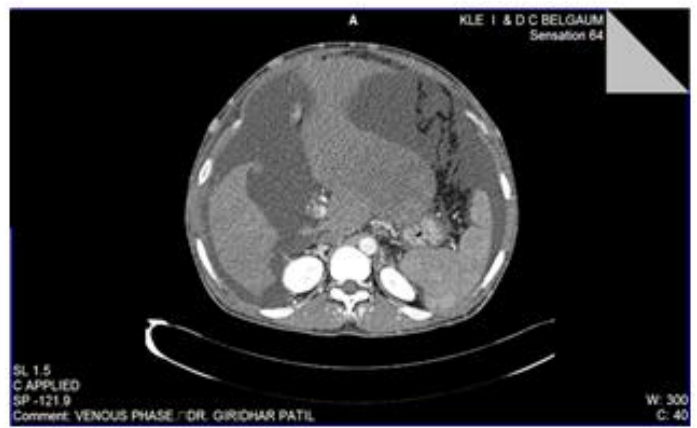

\section{Fig. 5: CT Abdomen- thrombus in Splenic Vein}

\section{REFERENCES:}

1. http://en.wikipedia.org/wiki/Inferior_vena_cava_syndrome.

2. Hartman DS, Hayes WS, Choyke PL, Tibbetts GP. From the archives of the AFIP. Leiomyosarcoma of the retro peritoneum and inferior vena cava: radiologic-pathologic correlation. Radio graphics. Nov 1992; 12(6):1203-20. [Medline].

3. Figueroa AJ, Stein JP, Lieskovsky G, Skinner DG. Adrenal cortical carcinoma associated with venous tumour thrombus extension. Br J Urol. Sep 1997; 80(3):397-400. [Medline].

4. http://emedicine.medscape.com

5. Tsuji Y, Inoue T, Murakami H, Hino Y, Matsuda H, Okita Y. Deep vein thrombosis caused by congenital interruption of the inferior vena cava - a case report. Angiology 2001; 52(10):721-5.

6. Barry J McAree, Mark E O’Donnell, Chris Boyd, Roy AJ Spence, Bernard Lee, Chee V Soong. Inferior Vena Cava Thrombosis in Young Adults - a review of two cases. Ulster Med J 2009; 78(2):129-133.

\section{AUTHORS:}

1. Giridhar Patil

2. N. V. Nimbal

3. Archana Dambal

4. M. P. Madhavaranga

\section{PARTICULARS OF CONTRIBUTORS:}

1. Assistant Professor, Department of General Medicine, BIMS Belgaum Karnataka.

2. Associate Professor, Department of General Medicine, BIMS Belgaum Karnataka.

FINANCIAL OR OTHER COMPETING INTERESTS: None
3. Assistant Professor, Department of General Medicine, BIMS Belgaum Karnataka.

4. Consultant Ophthalmologist, Department of Ophthalmology, Eye Hospital, Hubballi, Karnataka.

\section{NAME ADDRESS EMAIL ID OF THE} CORRESPONDING AUTHOR:

Dr. Giridhar Patil,

No. 26, Shanti Nagar, Tilakwadi,

Belgaum-590006.

E-mail: drgiridharpatil@gmail.com

Date of Submission: 10/02/2015.

Date of Peer Review: 11/02/2015.

Date of Acceptance: 23/02/2015.

Date of Publishing: 05/03/2015. 